\title{
Coupling of spatial and temporal pattern of cattle excreta patches on a low intensity pasture
}

\author{
Karl Auerswald · Franziska Mayer • \\ Hans Schnyder
}

Received: 23 May 2009/Accepted: 10 September 2009/Published online: 22 September 2009

(C) Springer Science+Business Media B.V. 2009

\begin{abstract}
Excreta deposition redistributes, separates and concentrates nutrients and thus affects sward heterogeneity and environment. Concentration occurs within excrement patches, but also at a larger scale when excreta are not randomly deposited. Thus, detecting excrement patterns and their underlying rules is essential to understand nutrient heterogeneity within a pasture. Two urine and six dung-patch distributions from six grazing periods were mapped on a 0.6 ha rotationally grazed cattle pasture. Excreta density was determined by creating Thiessen polygons. The Thiessen method was preferred to previously used predefined grids, because the resulting pattern is not obscured by the layout and resolution of such a grid. GIS, geostatistical simulation and geostatistical analysis were then applied to detect patterns. All urine and dung distributions had a similar dominant pattern with only small $(<5 \%)$ random variation. Excreta density increased with distance to the fence, decreasing slope gradient and towards the crest. The pattern evolved preferably during night at preferred resting areas when the animals rarely moved while urination and defecation
\end{abstract}

K. Auerswald $(\bowtie) \cdot H$. Schnyder

Lehrstuhl für Grünlandlehre, Technische Universität München, Am Hochanger 1, 85350 Freising, Germany

e-mail: auerswald@wzw.tum.de

F. Mayer

Institut für Agrarökologie, Landesanstalt für

Landwirtschaft, Lange Point 12, 85350 Freising, Germany were still served. Feed-back mechanisms attenuated some of the nocturnal pattern because resting places with high excrement density were avoided during grazing despite their high productivity. Validation with data from two independent studies showed that excrement patterns are common and governed by similar principles where site conditions are similar. Excrement pattern may be enhanced or attenuated by deliberate adjustment of pasture properties relative to terrain properties and the placement of installations such as fences. Placing watering or feeding stations close to preferred resting places and fences at a large distance to them will increase heterogeneity while night shedding would reduce it.

Keywords Autocorrelation - Diurnal pattern · Geostatistics · Nutrient cycle · Productivity · Spatial pattern $\cdot$ Thiessen area .

Anisotropic semivariogram

\section{Introduction}

Large herbivores are an integral part of grassland systems. Removal of nutrients by grazing and return by excretion lead to a cycling of nutrients, which in turn influences the structure and functioning of grassland systems (Haynes and Williams 1993). Nutrients are concentrated within the excreta patches and redistributed within the pasture. Redistribution will create a pattern, if some sites receive nutrients 
more frequently than others leading to nutrient enrichment in some locations while others are depleted. Furthermore, nitrogen and potassium are mainly excreted with urine, while phosphorus is deposited with the dung (Whitehead 2000). Thus, excreta deposition also separates nutrients. Plants depend on a balanced nutrient supply. The lower the excreta density and, thus, the further the distance between dung and urine patches the more difficult it may become to acquire sufficient nitrogen, potassium and phosphorus. Differing distances between dung and urine patches within the pasture may result in nutrient imbalances and, consequently, in heterogeneous biomass production (Hirata et al. 1991; MacDiarmid and Watkin 1971; Shiyomi et al. 1998) and species composition (Jaramillo and Detling 1992).

Thus far, several calculations of the statistical distribution of excreta patches exist. They distinguish random (Poisson), uniform and clumped (binominal) frequency distributions (Haynes and Williams 1993; Hirata et al. 1987, 1991; Petersen et al. 1956; Richards and Wolton 1976). According to Hirata et al. (1991) and Petersen et al. (1956) negative binomial distribution functions fit best for excreta distributions. However, distribution function analysis quantifies heterogeneity but cannot decide whether a pattern exists or not. This requires methods, which can separate pattern from noise like geostatistical methods, e.g. semivariogram analysis (Radeloff et al. 2000; Shiyomi et al. 1998). Such a spatial pattern of excretion may especially result from the temporal pattern of animal behaviour. A non-homogenous distribution of time spent for an activity in space (residence time) or a non-homogeneous intensity of the respective activity in time (activity rate per time) will create a pattern because intensity times residence time yields total activity. It is obvious, that the animals spend more time in the resting area than anywhere else. However, not all of their activities are concentrated to the same extent around their resting places, because some activities are low during resting, e.g. drinking (Browns 1971) or grazing (Krysl and Hess 1993). On the other hand, a pronounced spatial pattern should result from those activities, which occur at the same or even at a greater rate during resting.

This study investigates, (1) whether there is a spatial pattern of excretion and which site properties govern this, (2) whether there is a temporal pattern in the rate of excretion, (3) whether such a temporal pattern would dampen or amplify the spatial pattern created by uneven residence time, (4) which site properties govern the pattern and (5) how universal these effects are. This will be done by geostatistical analysis of excrement patch patterns. Besides ten own patterns differing in grazing periods, diurnal periods and excrements type this will also be done for pattern taken from literature to prove that the underlying mechanisms are of general applicability. A quantification of the strength of excrement patterns are missing so far because of a lack in suitable methods for pattern determination and analysis. The prerequisite for the analysis will hence be the development of a suitable approach.

\section{Materials and methods}

Study area

The investigations were carried out on the Scheyern experimental farm in the Tertiaerhuegelland landscape in southern Bavaria, Germany, about $40 \mathrm{~km}$ north of Munich. The relief is hilly with sandy soils on the crests and mostly steep south-western slopes and loamy loess covering the gentle north-eastern slopes (Sinowski and Auerswald 1999). The mean annual rainfall is about 900, $600 \mathrm{~mm}$ falling during the growing season, and the mean temperature 7.0$8.0^{\circ} \mathrm{C}$ (10-year averages).

The pasture was located on a north-facing slope and had an area of 0.63 ha (Fig. 1). The pasture had an almost rectangular shape with the long axis $(\sim 120 \mathrm{~m})$ oriented $\mathrm{N}-\mathrm{S}$ and extending from the foot slope $(\mathrm{N})$ to the crest $(\mathrm{S})$. The gradient of the slope was relatively shallow in the south $\left(6^{\circ}\right)$ and increased towards the north $\left(40^{\circ}\right)$. The height between the foot slope and the crest was $20 \mathrm{~m}$. The crest was flatter than the foot slope and was the preferred resting place especially during night. This likely resulted from a preference for flat resting places but also from a pronounced inversion situation during night time with, on long-term average, $2^{\circ} \mathrm{C}$ higher temperatures at the crest compared to the valley bottom with even larger differences during the late-night hours. The largest difference during late-night hours recorded in 8 years amounted to $11.6^{\circ} \mathrm{C}$.

The pasture had been used as a pasture for at least 50 years and was not fertilized for at least 10 years 


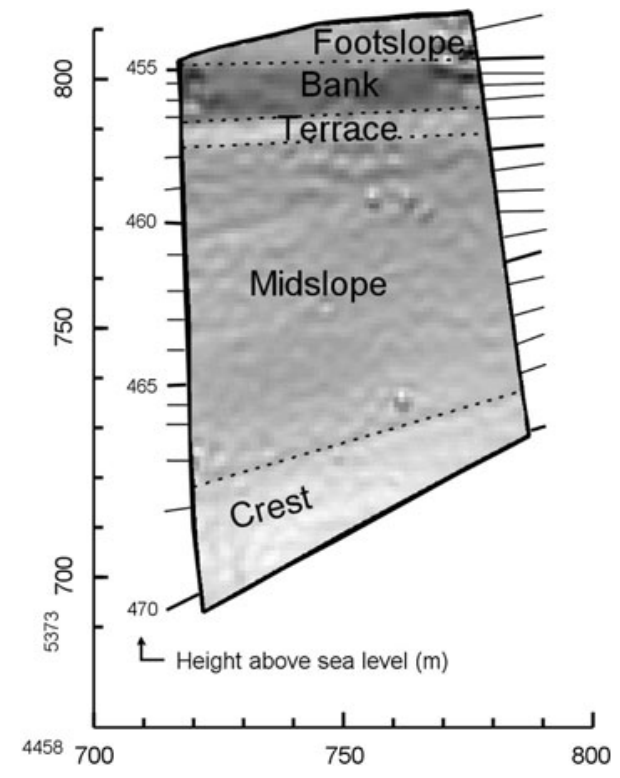

Fig. 1 Slope map from +5000 elevation measurements; the darker the grey the steeper the slope. Axes show GaussKrueger coordinates in meter; broken lines separate five geomorphologic units

preceding the study. Similar pastures were located to the east and west. A meadow adjoined to the north and was separated from the study pasture by a driving path. The south and higher side of the pasture was bordered by an arable field, which extended over the plateau.

The pasture was rotationally grazed, alternating with the pastures to the east and west, by a herd of about 25 (Table 1) suckler Simmental cows, their crossbred calves and an Angus bull. The cattle were kept on these pastures from May to October. A water tank was within the grazed area (NE corner) in 1993 and July 1994. Otherwise, it was outside and the cattle had free access to it through a gate at the NE corner and along the driving path. Excreta deposition outside the pasture was not measured.

Vegetation composition was determined in 69 relevées $\left(10 \times 10 \mathrm{~m}^{2}\right.$ blocks except for the margins). The following species contributing more than $1 \%$ each and a total of $90 \%$ to biomass (average contribution to biomass in \%): Poa trivialis (26), Taraxacum officinale (15), Alopecurus pratensis (11), Lolium perenne (9), Ranunculus repens (6), Dactylis glomerata (5), Trifolium repens (5), Agrostis tenuis (4), Elytringia repens (4), Festuca rubra subsp. commutata (3), Poa pratensis (2), Festuca arundinacea (2). Although floristic composition varied spatially (e.g. composition underneath fences differed from vegetation at preferred resting places), this factor is not further analyzed here, because it cannot be regarded as independent. Floristic composition is the result of site properties, including fertility and disturbance resulting from grazing and excretion behaviour. Hence we used independent site properties, which are not affected by the grazing animal, to explain the excretion behaviour, bearing in mind, that some of these factors may increase or decrease in strength over time by feed-back mechanisms acting via a change in vegetation properties. The factors selected were: the fence, the distance to the top or foot of the hill, the slope gradient and the position of the water tank.

\section{Excreta mapping}

Excreta were mapped six times for dung and two times for urine (details see Table 1). Dung patches

Table 1 Surveyed grazing periods, air temperature (measured at two stations at about $350 \mathrm{~m}$ distance to the site), stocking density and mapped excreta

\begin{tabular}{lllllllc}
\hline Date of grazing & \multicolumn{2}{l}{ Air temperature $\left({ }^{\circ} \mathrm{C}\right)$} & & Stocking density $\left(\mathrm{LU} \mathrm{ha}^{-1}\right)$ & Excrement type & Indication \\
\cline { 2 - 5 } & Minimum & Mean & Maximum & & Dung & Urine \\
\hline 12-18 May 93 & 6 & 53 & 24 & 53 & Dung May-1 \\
24-27 May 95 & 4 & 53 & 25 & 53 & Dung & D_May-2 \\
31 May-02 Jun 96 & 4 & 53 & 29 & 53 & Dung, urine & D_Jun & U_Jun \\
21-26 Jul 93 & 9 & 53 & 24 & 53 & Dung & D_Jul-1 \\
18-20 Jul 94 & 16 & 53 & 30 & 53 & Dung, urine & D_Jul-2 & U_Jul \\
07-09 Sep 94 & 10 & 65 & 25 & 65 & Dung & D_Sep \\
\hline
\end{tabular}

$L U$ Livestock unit 
were identified after each grazing period, lasting about 3 days, while urine patches were determined either during daylight hours (U_Jul: 4:30 to 21:30; about $80 \%$ of all patches) or by $24 \mathrm{~h}$ observation of the pasture (U_Jun; a full moon period) and immediate marking of each urine patch position with a stick. The full-moon period in 1996 allowed also determining the diurnal pattern by additionally recording the time of excretion. Some dung excretion may have happened while an animal was moving. As most of the pasture was steep and the flat areas were small, the animals did not move fast and thus kept this problem small. Nevertheless, some dung excreta in the flat areas with high dung density may have been overlooked and the true pattern may be slightly more pronounced than identified by out analysis. The problem does not apply to the immediately marked urine patches and temporally resolved data.

The central position of each excreta patch, defined in a Gauss-Krueger coordinate system, was geodetically determined by angle and distance measurements using a digital tacheometer (Leica TC 1600). The $z$ coordinate (height above sea level given in meters a.s.1.) allowed a detailed digital elevation model of the pasture to be created using the 3DAnalyst (ArcView GIS 3.2 by ESRI, Kranzberg, Germany) on the $5000+$ data points $\mathrm{ha}^{-1}$.

Data analysis

To determine excreta density without bias and with the highest possible spatial resolution, the density was calculated for each patch position by constructing its Thiessen area. The perimeter of the Thiessen area is given by the middle lines between neighbouring patches. It is determined by connecting the crossing points of the perpendicular bisectors of the interconnections between patch centres (Goovaerts 2000; Thiessen and Alter 1911; computed by ArcView applying the ArcScript thiessen.avx by Greg Ammon available at http://gis.esri.com/arcscripts/ index.cfm). The reciprocal value of the Thiessen area then represents the excreta density within each Thiessen polygon. An example for the construction of Thiessen polygons from dung coordinates and the resulting dung density map is given in Fig. 2. To allow for a comparison of different excreta types or grazing periods despite the varying number of patches (dependent on excreta type, stocking density and

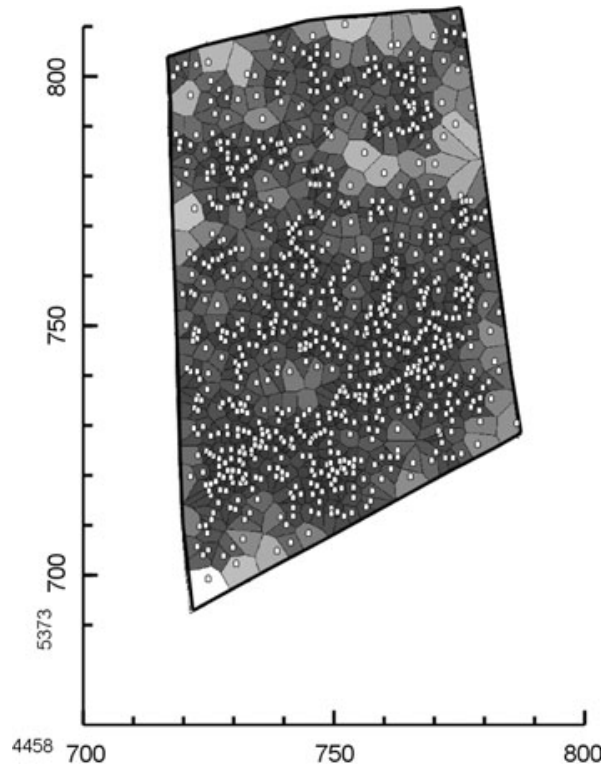

Fig. 2 Calculation of Thiessen polygons (lines) from the dung patch (circles) distribution. The darker the grey the smaller the polygon area and the higher dung density. Axes give GaussKrueger coordinates in meter (Survey: D_Jul-1)

grazing period) the Thiessen areas were also normalized according to the average Thiessen area of an excreta type and a grazing period.

GIS (ArcView GIS 3.2 by ESRI) was used to visualize the data and to perform spatial data analysis. SAS (version 8; SAS Institute, Cary, USA) was used for geostatistical analysis. As patch densities were not normally distributed, a log-transformation was carried out before applying geostatistics. The location of measurement was not independent from the measured value, which causes less data points in areas of low density. A simple regular or random resampling of the area is insufficient as the Thiessen polygons do not yield information about the spatial variation of first, second and higher order properties within each polygon. A resampling would thus underrate the variation within the range of the polygons. To avoid any bias in the geostatistical analysis, stochastic simulation methodology (Deutsch and Journel 1992) was used to create similar data density over the whole pasture. The simulation was based on the assumption that an excreta patch could have been deposited anywhere within its Thiessen polygon but not beyond. A new position within each polygon was then defined at random and new Thiessen polygons were calculated for the new positions. This procedure 
was repeated ten times. From this data set of ten simulations additional positions with their Thiessen areas were selected and combined with measured positions to meet the optimization criterion of homogenous data density over the whole pasture (Van Groenigen and Stein 1998). This procedure accounts for the uncertainty of the Thiessen polygons while resampling the original Thiessen polygons at fixed predefined homogenously distributed positions would return the same value for each position within one (large) Thiessen polygon and thus underrate the small-distance variation.

Experimental semivariograms of patch densities were computed to determine the extent and range of autocorrelation. To quantify the cross-correlation between dung and urine pattern pseudo cross-variograms (Papritz et al. 1993) were calculated using the gstat procedure of $R$ (Pebesma 2004). Semivariograms quantify the average dissimilarity (= semivariance) of a property (e.g. patch density) depending on the distance between points of interest (= lag). Semivariance may change with lag independent of direction (= isotropic) or this change may depend on direction (= anisotropic), e.g. when the relation along the slope differs from the relation across the slope (Zimmerman 1993). The intercept on the $y$ axis (semivariance for zero lag) is called nugget effect and quantifies local variability or "noise" within the data. Where semivariance approaches a plateau, this is called sill. The sill of the semivariogram quantifies the variation in patch density over distances beyond the range of the autocorrelation. A large difference between sill and nugget effect indicates a pronounced spatial pattern, while no spatial pattern exists where the sill equals the nugget effect. The lag distance until the sill is reached is called range. It quantifies the maximum distance of spatial autocorrelation whereas data pairs at distances larger than the range can be regarded to be independent. An experimental semivariogram may be composed of several nested semivariograms differing in range and sill when more than one processes operating at different scales contribute to the spatial pattern (Burrough 1983). It may appear that the lag and the semivariance both contain the same property, namely the distance of the patches, and hence, that they are not formally independent. A formal dependence, however, does not exist: (1) the lag is calculated from two patches while the two Thiessen polygons are calculated from many patches and two adjacent polygons can have no more than two corners in common. (2) Our simulation generated additional data points to ensure homogeneous data density. At short distances where this formal similarity may be relevant, the lag is calculated from a measured and a simulated data point, while in the calculation of the Thiessen areas the measured and the simulated data points are not jointly considered (otherwise Thiessen areas would become identical over the whole pasture because the simulated data points ensured a homogeneous sampling density over the whole pasture).

Kernel density estimation (Victor 1978; Silverman 1986) was used to quantify the temporal variation in excretion activity. Kernel density is preferable to obtain a high resolution in frequency distribution of highly skewed, possibly multimodal data. The first and the last hour of the day were added to the other end of the day prior to kernel density estimation for a 26-h period to ensure a correct estimation also at midnight. After estimation, the first and the last hour were deleted to extract the 24-h period.

Pearson correlation analysis and multiple regressions between excreta density and supposed explanatory variables were performed. For a statistical analysis and causal interpretation, the explanatory variables have to be independent from each other. This was given:

1. The slope gradient generally increased from the hill top to the foot. However, there were zones of shallow slope on the top (crest) as well as in the middle part (terrace) or at the footslope (Fig. 1).

2. The pasture was rectangular but the southern fence was set to a deviating angle. Thus, the influence of the fence decreased from the southwestern corner where the fence opens with an angle of $60^{\circ}$ to corners with $90^{\circ}$ and $120^{\circ}$. The least influence of the fence is found in the centre.

3. The water tank was within the grazed area for the surveys D_May-1, D_Jul-1, D_Jul-2 and U_Jul but outside otherwise.

\section{Validation}

Site conditions are unique. Given that site conditions create an excrement pattern, each pattern must be unique. Thus, it has to be validated whether pattern characterized by a pronounced autocorrelation are a common phenomenon and whether similar principles 
govern the pattern where site conditions are similar. Data were taken from Hirata et al. (1987) and White et al. (2001). Their maps of excrement patches were digitised and then treated the same way as our data.

\section{Results}

Mapping of excreta

Between 526 and 1194 dung patches and between 273 and 426 urine patches were recorded per grazing period (Table 2). This led to average densities of about one dung patch per $7 \mathrm{~m}^{2}$ and one urine patch per $8 \mathrm{~m}^{2}$ for the whole-day recording at full moon.
The maps (Fig. 3), however, revealed a large spatial variation and some similarity in the underlying pattern. Patch density was higher in the SW and decreased to the NE.

The mean distance between neighbouring dung patches deposited during one grazing period varied between 1.3 and $2.4 \mathrm{~m}$ (Table 2). However, maximum distances to the nearest neighbour of up to $7.9 \mathrm{~m}$ were observed. Assuming dung patch diameters of 0.26-0.34 m (Whitehead 2000), each grazing period also yielded overlapping patches. Mean distances of urine patches to the nearest neighbour were larger and varied between 1.7 and $2.2 \mathrm{~m}$, with a maximum of $8.9 \mathrm{~m}$ and a minimum of 0.01 . Thus, with urine patch diameters larger than $0.46 \mathrm{~m}$

Table 2 Statistical parameters of excrement patch distribution

\begin{tabular}{|c|c|c|c|c|c|c|c|c|}
\hline & D_May-1 & D_May-2 & D_Jun & D_Jul-1 & D_Jul-2 & D_Sep & U_Jul & U_Jun \\
\hline$n$ & 1194 & 640 & 749 & 828 & 534 & 526 & 273 & 426 \\
\hline$n / \mathrm{LU} / \mathrm{d}$ & 3 & 6 & 8 & 3 & 5 & 4 & 2 & 4 \\
\hline \multicolumn{9}{|c|}{ Distance to nearest neighbour (m) } \\
\hline Mean & 1.38 & 1.69 & 1.29 & 2.37 & 1.59 & 1.73 & 2.22 & 1.74 \\
\hline Max & 3.80 & 6.90 & 7.10 & 3.88 & 7.88 & 5.71 & 8.20 & 8.94 \\
\hline Min & 0.05 & 0.01 & 0.01 & 0.26 & 0.01 & 0.06 & 0.21 & 0.01 \\
\hline Median & 1.29 & 1.55 & 1.11 & 2.19 & 1.34 & 1.63 & 1.94 & 1.58 \\
\hline $\mathrm{CV}$ & 0.36 & 0.48 & 0.64 & 0.31 & 0.59 & 0.49 & 0.62 & 0.62 \\
\hline \multicolumn{9}{|c|}{ Thiessen area $\left(\mathrm{m}^{2}\right)$} \\
\hline Mean & 5.4 & 9.9 & 8.5 & 15.2 & 11.9 & 12.0 & 23.2 & 14.9 \\
\hline Max & 35.7 & 58.9 & 98.9 & 37.2 & 69.2 & 56.9 & 160.0 & 97.8 \\
\hline Min & 0.7 & 1.3 & 0.5 & 3.9 & 0.7 & 0.9 & 1.2 & 1.0 \\
\hline Median & 4.1 & 8.2 & 5.6 & 11.9 & 8.3 & 10.1 & 18.7 & 11.2 \\
\hline $\mathrm{CV}$ & 0.8 & 0.7 & 1.2 & 0.6 & 0.9 & 0.7 & 0.9 & 0.9 \\
\hline \multicolumn{9}{|c|}{ Thiessen area (rel.) } \\
\hline Mean & 1.00 & 1.00 & 1.00 & 1.00 & 1.00 & 1.00 & 1.00 & 1.00 \\
\hline Max & 6.66 & 5.96 & 11.69 & 2.45 & 5.84 & 4.73 & 6.90 & 6.58 \\
\hline Min & 0.14 & 0.13 & 0.06 & 0.26 & 0.06 & 0.08 & 0.05 & 0.07 \\
\hline Median & 0.77 & 0.83 & 0.66 & 0.78 & 0.70 & 0.84 & 0.81 & 0.76 \\
\hline $\mathrm{CV}$ & 0.76 & 0.69 & 1.23 & 0.63 & 0.86 & 0.70 & 0.92 & 0.88 \\
\hline \multicolumn{9}{|c|}{ Density $\left(\mathrm{m}^{-2}\right)$} \\
\hline Mean & 0.31 & 0.15 & 0.24 & 0.09 & 0.16 & 0.13 & 0.11 & 0.08 \\
\hline Max & 1.35 & 0.80 & 1.93 & 0.26 & 1.36 & 1.07 & 0.81 & 1.01 \\
\hline Min & 0.03 & 0.02 & 0.01 & 0.03 & 0.02 & 0.02 & 0.01 & 0.01 \\
\hline Median & 0.24 & 0.12 & 0.18 & 0.08 & 0.12 & 0.10 & 0.05 & 0.05 \\
\hline $\mathrm{CV}$ & 0.71 & 0.71 & 0.94 & 0.60 & 0.84 & 0.80 & 1.23 & 0.97 \\
\hline
\end{tabular}

$n$ : total number of excreta; $n /$ LU/d: number of excreta per livestock unit and day; for U_Jul urination was only recorded between 4:30 and 21:30; Max: maximum value; Min: minimum value; CV: coefficient of variance; $\mathrm{LU}$ : Livestock unit 
Fig. 3 The distribution of dung and urine patches on a rotationally grazed, low intensity pasture (abbreviations indicate month according to Table 1; $W$ watering place; axes give Gauss-Krueger coordinates in meter)

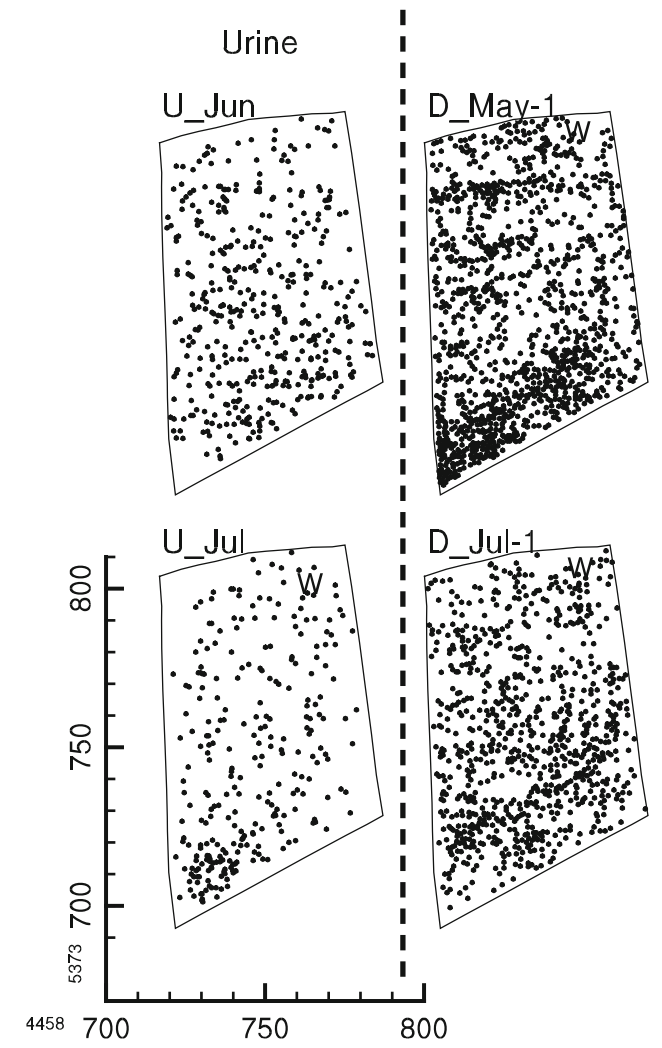

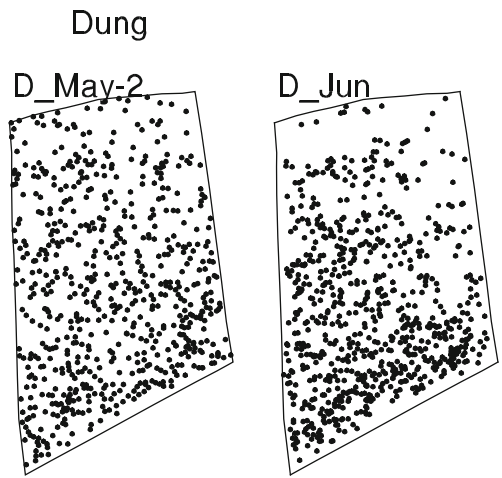
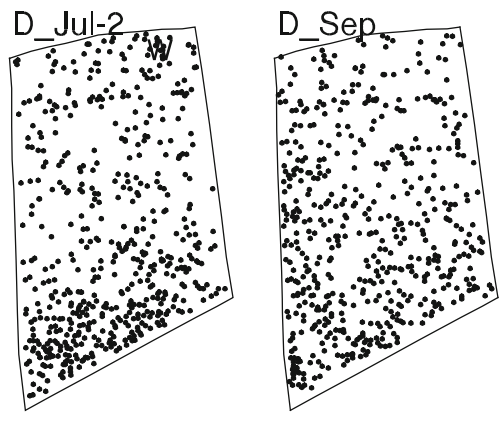

(Whitehead 2000) also some urine patches have overlapped.

The mean dung patch density varied between 0.1 and $0.3 \mathrm{~m}^{-2}$, while mean urine patch density was about $0.1 \mathrm{~m}^{-2}$. Maximum densities of 1.9 or $1.0 \mathrm{~m}^{-2}$ were reached for dung and urine, respectively. The coefficient of variance (CV) indicated a similar heterogeneity for all surveys. The maximum distances to the nearest neighbour had a strong effect on $\mathrm{CV}$, as maximum distance and $\mathrm{CV}$ were relatively highly correlated $(r=0.71)$ while $\mathrm{CV}$ was independent of the mean.

The frequencies of relative Thiessen areas were log-normally distributed and similar for all of the eight observations (Table 2). In all surveys, the patch density and hence the nutrient supply within this small pasture varied by much more than one order of magnitude, even if the concentration of nutrients within the patch itself is not considered.

Spatial analysis

All semivariograms indicated a clear pattern with little noise (average nugget effect 0.01 ; SD 0.004) contributing less than $5 \%$ to the maximum semivariance in all cases. The semivariances of all excrement distributions were rather similar as indicated by the small SD for the nugget effect. Also for the sill and range $\mathrm{SD}$ among the excrement patch distributions was small $(<20 \%$ of the mean). Even the grazing period with a water tank on the pasture did not deviate from those without water tank. Hence the semivariances of all survey could be pooled (Voltz and Webster 1990) to yield the average behaviour (Fig. 4).

The same conclusion could be drawn from the pseudo cross-variograms (not shown), which were similar in shape to the simple semivariograms. The main and consistent difference between all simple semivariograms and the respective pseudo crossvariograms was that the nugget effect of the pseudo cross-variograms was considerably larger, contributing usually half of the total sill. This reflects that the excreta of two observations (either two periods in time or two excreta types) do not fall on identical positions but the general, pasture-wide pattern of excreta distributions remained similar.

The semivariograms were governed by three properties, which relate to different reasons for the 


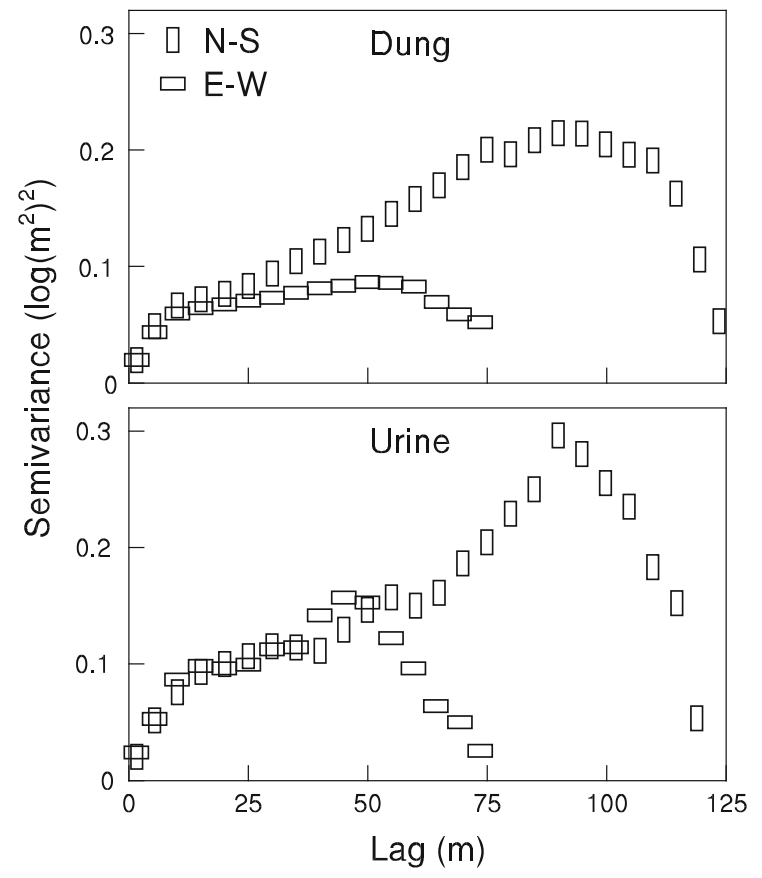

Fig. 4 Anisotropic semivariograms of Thiessen areas pooled for all dung (top) and all urine surveys (bottom); $N-S$ is along the slope while $E-W$ is the short pasture axis across the slope

pattern: (1) a pronounced "hole effect", which in geostatistics denotes decreasing semivariances at large distances similar to the semivariogram for the sides of a hole that will always be similar in height, (2) a pronounced anisotropy along and across the slope, and (3) a pronounced small-scale $(<15 \mathrm{~m})$ and a large-scale $(100 \mathrm{~m})$ pattern. The three effects will be looked at below.

(1) The hole effect is caused by the fence. The decrease of semivariance at large distances indicated that the areas close to the fence at both sides were similar despite their large distance. It was evident for $\mathrm{N}-\mathrm{S}$ and $\mathrm{E}-\mathrm{W}$ directions and for dung and urine patches. The excreta distribution maps (Figs. 2, 3) show that patch density along the fences was below average. The range of the fence effect, given by the decreasing semivariance at large distances, was about $25 \mathrm{~m}$ in all cases and thus covered a remarkable proportion of the pasture.

(2) The anisotropy is caused by the larger variation of topographic attributes along the slope than across the slope. The maximum semivariance is two to three times larger along the slope than across the slope indicating that topography is responsible for most of the pattern. Among topographic attributes slope gradient had the largest influence. Excrement density sharply decreased above a slope gradient of $20 \%$ (Fig. 5). However, even at gradients $<5 \%$ there was a large variation in excrement density coving more than one order of magnitude. The reason for this variation is mainly related to altitude. The flat crest, which was a preferred resting place, received more excrements than the similarly flat but narrow terrace (Fig. 1). This becomes evident when comparing both flat areas in Fig. 3 (especially U_Jul, D-May-1, D_Jun and D-Jul-2).

(3) While the large-scale pattern only appears in the $\mathrm{N}-\mathrm{S}$ semivariograms and hence relates to the topographic attributes, there is also a small scale variation. This disappears at large lags (hole effect) and hence relates to the fence.

As dung and urine distribution patterns were similar but not equal, their superimposition-yielding dung-urine distance distributions-resulted in a less obvious pattern than those of the single distributions. The distances between the $\mathrm{K}$ rich urine patches and the $\mathrm{P}$ rich dung patches were hence less variable than the distances between $\mathrm{K}$ rich patches or $\mathrm{P}$ rich patches, because large $\mathrm{P}-\mathrm{K}$ distances need the combination of large $\mathrm{K}-\mathrm{K}$ distances and large $\mathrm{P}-\mathrm{P}$ distances. Plants will hence have similar problems on the whole pasture to access both nutrients together from excreta patches. The aerial proportion of dungurine distances followed a log-normal distribution

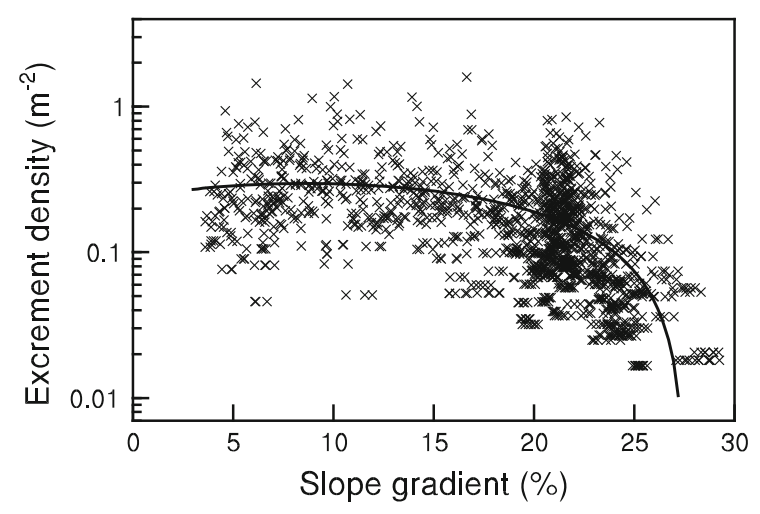

Fig. 5 Influence of slope gradient on dung density (line is a parabolic regression; $R^{2}=0.209$ ) 
(Fig. 6) with a minimum distance of $1.5 \mathrm{~m}$ being most likely. The minimum distance between dung and urine patches was less than $0.8 \mathrm{~m}$ on $10 \%$ of the total pasture area and smaller than $2.0 \mathrm{~m}$ on $50 \%$ of the area. Conversely, the distance of $\mathrm{K}$ rich (urine) and $\mathrm{P}$ rich (dung) patches was larger than $2.9 \mathrm{~m}$ on one quarter of the pasture area with some distances extending more than $8 \mathrm{~m}$.

\section{Correlation with site properties}

In all cases the Thiessen area per patch increased (= decrease in density) with slope, indicating that there was less excretion on the steeper parts (Fig. 5). All correlations were highly significant $(P<0.01)$, although the regressions explained only $10-35 \%$ of the variance with logarithms for both variables. Patch density also increased from the bottom to the top of the slope indicating that the cattle preferred the topslope positions. The top slope was windier during the day and much warmer during the night due to a pronounced temperature inversion effect. Differences in night temperature between top and bottom amounted up to $12^{\circ} \mathrm{C}$ during the grazing period, in spite of the short distance. Adding the fence effect and the height above sea level in a multiple linear regression increased the multiple correlation coefficient by up to 0.15 . The increase was significant in most cases for both variables. Accordingly, up to $44 \%$ of the variance was explained by the three variables. These still relatively weak correlations demonstrate that (multiple) regressions alone were not appropriate to identify spatial patterns and underlying relationships.

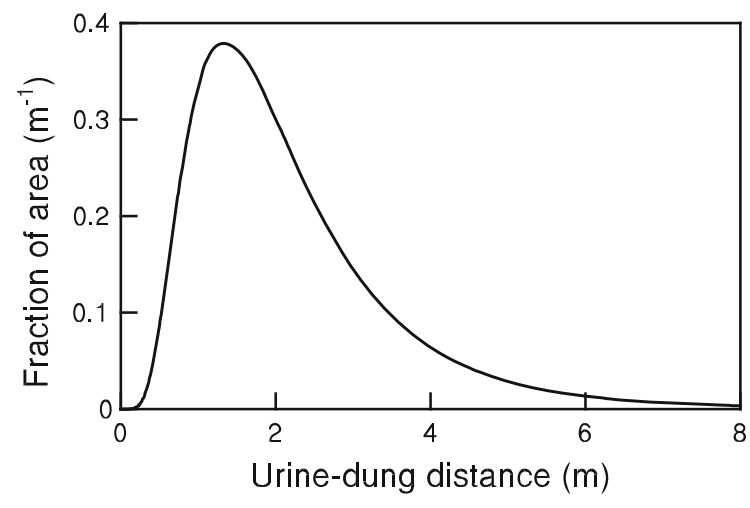

Fig. 6 Fraction of area occupied by different urine-dung distances
Temporal analysis

Dung deposition and urination exhibited similar temporal patterns with maxima around 10:00 and 17:00 and also a minimum around midnight (Fig. 7). Activity had a minimum around midnight, but still occurred at a considerable rate. Combining both excretion activities yielded a minimum activity that was still about half of the maximum. Diurnal variation in excretion was less than that known for grazing, which has two maxima, one after dawn and one before dusk (Arnold 1981).

The low incentive to move during resting time while digestion paced on should have caused a concentration of excreta in the resting area during night time hours. This was confirmed by the excretapatch semivariograms, when excreta distribution patterns from daylight and night-time hours were compared (Fig. 8). During daylight the maximum semivariance was lower and the fence effect extended only about $10 \mathrm{~m}$ into the pasture, indicating a relatively even excreta distribution.

The spatial pattern of dung and urine distribution clearly showed a high excreta density in the southern part of the pasture during the night and a marked decrease to the northern end (Fig. 9). The crest was the preferred resting area. During daylight the excreta were more evenly distributed. The most evident feature was a low patch density in the crest area. This likely resulted from avoidance of this dung-dense resting area during grazing (Marten and Donker 1964; Luetge et al. 1995). Excreta deposition in that area was only half of that produced during night for dung and only one-fifth of that for urine. Some of the

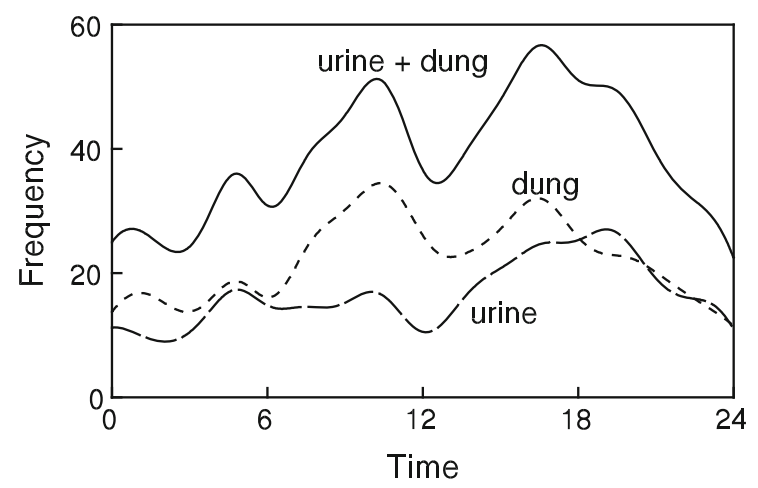

Fig. 7 Diurnal rhythm in excretion activities of grazing suckler cows (Kernel density estimation) 


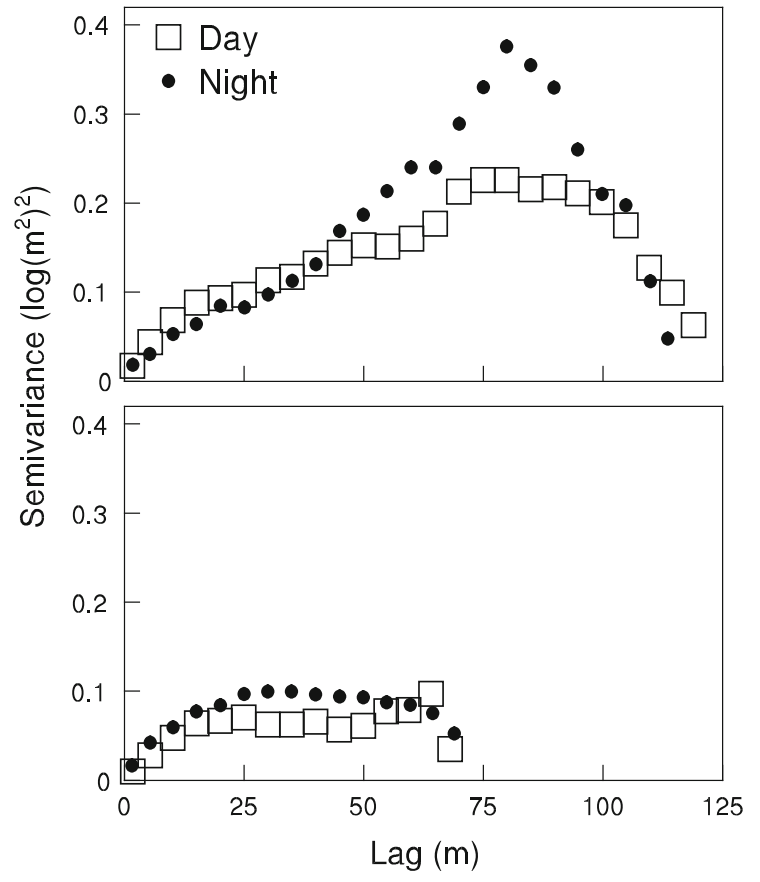

Fig. 8 Anisotopic semivariograms for excreta density (dun$\mathrm{g}+$ urine) produced during daylight (6:00-21:00) and night time. Top: $N-S$ along the slope, bottom: $E-W$ across the slope
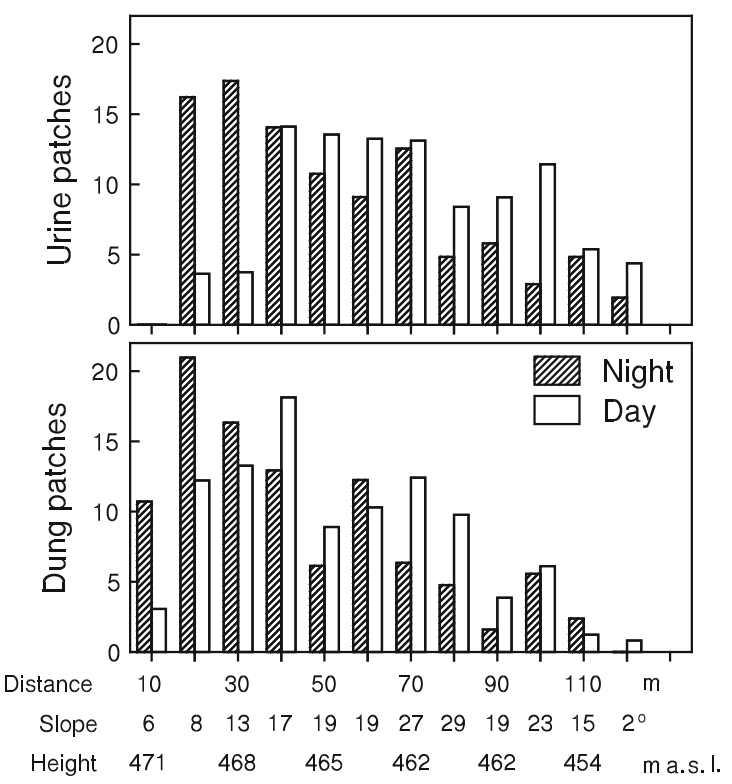

Fig. 9 Distribution of urine and dung patches in percent per unit area with increasing distance from the southern fence

increase in semivariance with lag during day time was thus caused by a pattern partly opposite to the pattern produced during night time.
Validation studies

The semivariograms of the validation studies also indicated a pronounced pattern. The maximum semivariance was about the same as in our case although the maximum lag was shorter due to the shorter pasture axes in the validation studies. The semivariograms were similar to our semivariograms except for some details caused by the different site conditions (Fig. 10).

In the study of Hirata et al. (1987) the semivariograms almost show no anisotropy due to the small and almost square pasture shape (Fig. 10c). Most

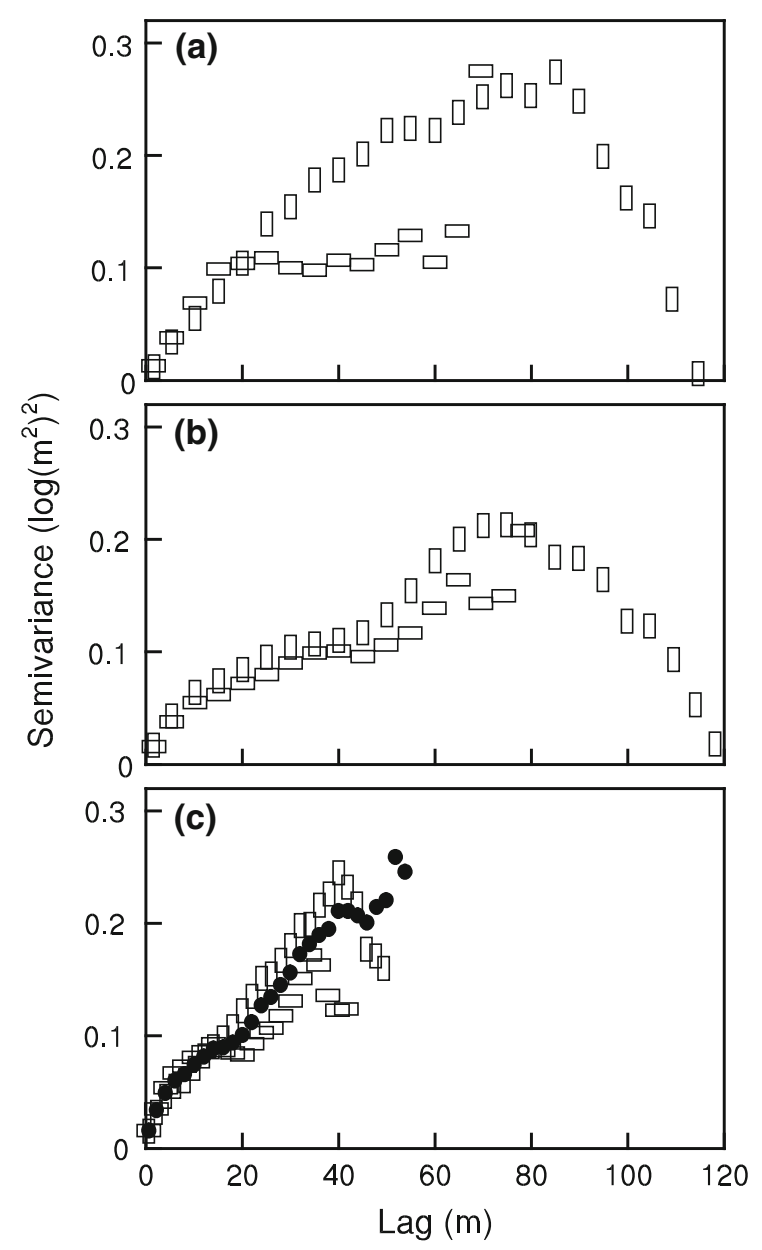

Fig. 10 Semivariograms for excreta density of validation studies. a White et al. (2001), urine. b White et al. (2001), dung. c Hirata et al. (1987) dung. Upright and horizontal symbols show semivariance in direction of the long and the short side of the pastures respectively, circles give isotropic semivariance 
pronounced, the hole effect is almost missing in this study because the opposite sides of their pasture instead of being similar were characterized by a large contrast. While there was a repellent fence on the western and southern edge of the pasture, the fences at the eastern and northern edge were replaced by two attracting installations, namely a shaded resting place at the eastern edge and a water trough at the northern edge. In consequence the north-eastern corner was most attractive receiving most excrements while the south-western corner was most repellent receiving least excrements. The isotropic semivariance thus increased over the largest possible distance from the north-eastern to the south-eastern corner and a sill could not be found within the maximum possible distance.

The semivariograms for the data of White et al. (2001) were almost identical to our semivariograms. There was a clear fence effect, which expanded about $25 \mathrm{~m}$ into the pasture. The anisotropy is somewhat smaller given the smaller difference in length between both axes of the pasture and the almost flat terrain.

\section{Discussion}

Methodological approach

The answer to whether excreta of grazing cattle are distributed randomly or follow a pattern strongly depends on the choice of appropriate methods. Thus far, the distribution of excreta has been analyzed mainly statistically (Petersen et al. 1956; Richards and Wolton 1976), and there have been few attempts to describe it spatially (Peterson and Gerrish 1995; White et al. 2001) or even to quantify spatial patterns. In order to understand nutrient fluxes in pasture ecosystems, we need to quantify spatial relationships among components, processes and their causes.

Most of the calculations to determine the type of statistical distributions have been based on point or grid data. For example, the probability measure of Richards and Wolton (1976) or the dispersion coefficients mentioned by Green (1966) need patches per area (counted in each grid cell) as basic data. This involves the problem of choosing the appropriate grid, which affects the resulting type of distribution (Braun and Lachnit 1994) as the grid will destroy at least some of the underlying pattern. A method applying continuous data is the distance measure considered by Clark and Evans (1954), which, however, depends on the number of samples while independence from sample size is essential (Green 1966). Geostatistical analysis of Thiessen areas is independent of grid or sample size and has clearly revealed a spatial structure in all data. Hence it is superior to previously used grid methods to compute excreta densities because the polygons depend solely on the local density of excreta patches.

Geostatistical analysis showed that excreta distribution had only a small random component (nugget effect between 0.005 and 0.02). The nugget effect of the pseudo cross-variograms was larger (up to 0.1), which is generally found and which is due to different nature of the nugget in the auto-variogram and the cross-variogram (Lark 2002). Most of the variation was due to a spatial pattern (maximum semivariance between 0.16 and 0.40 during night). Thus, random variation contributed only about $5 \%$ to the total variation of the individual surveys. In contrast, multiple regression analysis explained only 16-44\% and thus attributed most of the variation to unexplained random variation. Previous studies, which used predefined pattern and regression analysis, are likely to have strongly underrated the contribution of pattern and overrated the random variation. This is because multiple regression does not examine the similarity of neighbouring areas, which characterizes pattern. In addition, especially slope gradients can only be derived with relatively large error even from dense geodetic data (Warren et al. 2004; see also the small-range variation in Fig. 1). And finally, the random error of a multiple regression is large, where the multiple regression does not describe the underlying mechanisms and interactions even if there is a pronounced pattern. On the other hand, the nugget to sill ratio of geostatistical analysis measures the intensity of the pattern, irrespective of underlying mechanisms. Nevertheless, knowledge about the existence of a pattern and its spatial structure facilitates the investigation of site properties to explain any pattern.

\section{Temporal pattern}

The temporal pattern of excretion was much weaker than the temporal pattern of grazing reported in 
many studies (Arnold 1981; van Soest 1994; Linnane et al. 2001). This is caused by the high frequency of excreta production, in particular typical for ruminants. In contrast, for example, the much smaller excretion frequency of man is related closely to a circadian regulation of gastrointestinal functions (Hastings 2002). Hence a distinct diurnal variation in urine secretion exist for human adults (Steffee et al. 1981). The relatively steady rate of excretion by cattle, in conjunction with an extended residence time in the resting area was the main factor giving rise to the strong spatial pattern of excreta distribution.

\section{Influence of site properties}

In the present study, the pattern was caused by the three site properties, slope gradient, height above sea level, and the distance to the fence, while the location of the water tank had no clear effect. Except for the water tank, these variables seem to influence mainly resting. The relationship between excreta density and the slope gradient is already known (Haynes and Williams 1993). The effect of the position within the slope (height) has not been described before and is caused by the pronounced temperature inversion during night at this site. In contrast to our data, Petersen et al. (1956) found increasing excreta density near the boundary fence because they only made observations during daylight. Such behaviour during daylight would also follow from our almost reciprocal patterns during daylight and night time resulting from the avoidance of areas with high excrement density during grazing. Cattle reject for a period of time herbage growing near dung patches (Hirata et al. 1987; Lantinga et al. 1987, 1995; Marten and Donker 1964). Schnyder et al. (this volume) also observed that herbage removal was less in the areas of excrement accumulation despite a large amount and quality of herbage. This agrees with our observation of an avoidance of resting places during grazing. The dense dung patch deposition created during resting thus is attenuated during grazing and decreases the influence of site conditions.

On the other hand, urine patches might be preferred for grazing, especially in the next grazing period (Day and Detling 1990; Lantinga et al. 1987; Luetge et al. 1995). Thus, urine patches should intensify the pattern. However, the two effects of cattle's foraging behaviour, urine patch preference and dung patch avoidance, affect both urine and dung distribution. Thus, the attenuation and the intensification of the site dependent pattern are not independent but may be superimposed on each other.

The patterns of excreta distribution as shown here are directly relevant to the nutrient relations within the pasture community (Schnyder et al., this volume). Excreta patches are sites of high (although unbalanced) nutrient availability, whereas the space between excreta patches may be depleted of nutrients. Thus, in the present unfertilised pasture, any patch of vegetation experienced several defoliations per year, with each defoliation causing significant removal of plant-internal nutrients. In contrast, local nutrient returns in the form of excreta were sporadic, with a $50 \%$ probability of local return over 1-10 years, depending on the location in the pasture and the form of nutrient return (dung or urine). A plant's ability to recover the nutrients lost via defoliation will depend on its ability to effectively garner nutrients in the face of spatio-temporal heterogeneity of nutrient distribution. Species may differ strongly in the morphological and physiological features, which determine nutrient acquisition in such heterogeneous environments (Huber-Sannwald and Jackson 2001). Hence excreta distribution, through effects at both small and large scales, may directly influence the biotic diversity and patchiness of the grazed ecosystem (Kirkham and Kent 1997; Landsberg et al. 2002).

\section{Validation studies}

The validation studies proved that the deposition of excrements follows a clear pattern and that the pattern is governed by similar principles where driving forces are similar. This could especially be shown for installations that can either be repellent (fence) or attractive (watering place). The effect of topography could not be detected during validation due to lack in variation in these studies. The strong autocorrelation is especially remarkable for the study of White et al. (2001) because the authors explicitly had stated that there was no pattern in their excrement distribution except for some aggregation of excrements around the watering place. This perception is the consequence of the method to count excrements in predefined sectors, which destroys most of the pattern. 


\section{Conclusions}

We proposed a new method in geostatistical analysis of excrement-patch distribution, which is independent of any predefined sectors that partly destroy the pattern to be analyzed. The geostatistical analysis revealed that the pattern of excrement distribution is considerably stronger than quantified in previous studies. The random component contributed less than $5 \%$ to the pronounced excreta pattern. The main site properties creating the pattern in our case were: (1) the fence: its influence extended to about $25 \mathrm{~m}$ and led to a low patch density in its proximity; (2) the slope gradient; (3) the slope position: this was a major influence presumably because of its control on nighttime temperature, which affected stock behaviour. Gradient and position resulted in an aggregation of excreta on the flatter and higher parts of the pasture. These influences created the pattern mainly during resting time, while the pattern was partly attenuated during grazing. Urination and defecation, which do not involve displacement, were served at still a high rate during resting. This caused the concentration of excreta in the resting area. On heterogeneous pastures with preferred resting areas the diurnal activity pattern will thus yield a spatial pattern of excreta deposition and hence nutrient return. Where the heterogeneous nutrient distribution caused by dung and urine is regarded undesirable, over-night shedding may be a solution. A re-analysis of patch distributions taken from literature proved the general applicability of the principles given that site conditions are similar.

Acknowledgments The present study was part of the research network "Forschungsverbund Agrarökosysteme München" (FAM) and financially supported by the Federal Ministry of Research and Technology (BMBF 0339370) and the Bavarian State Ministry for Education and Culture, Science and Art. We wish to thank Dr Herta König and Ulrike Schütz for making the data set available for analysis.

\section{References}

Arnold GW (1981) Grazing behaviour. In: Morley FHW (ed) Grazing Animals. Elsevier, Amsterdam, pp 79-104

Braun PW, Lachnit B (1994) Kennzeichnung der räumlichen Verteilung von Pflanzenpopulationen. Z Agrarinformatik 4:67-71

Browns JE (1971) Sheep behaviour under unherded conditions on mountain summer ranges. J Range Manage 24: 105-109
Burrough PA (1983) Multiscale sources of spatial variation in soil. II. A non-Brownian fractal model and its application in soil survey. J Soil Sci 34:599-620

Clark PJ, Evans FC (1954) Distance to nearest neighbor as a measure of spatial relationships in populations. Ecology 35:445-453

Day TA, Detling JK (1990) Grassland patch dynamics and herbivore grazing preference following urine deposition. Ecology 71:180-188

Deutsch CV, Journel AG (1992) GSLIB-Geostatistical software library and user's guide. Oxford University Press, New York

Goovaerts P (2000) Geostatistical approaches for incorporating elevation into the spatial interpolation of rainfall. J Hydrol 228:113-129

Green RH (1966) Measurement of non-randomness in spatial distribution. Res Popul Ecol 8:1-7

Hastings MH (2002) Circadian rhythms: a gut feeling for time. Nature 417:391-392

Haynes RJ, Williams PH (1993) Nutrient cycling and soil fertility in the grazed pasture ecosystem. Adv Agron 49:119-199

Hirata M, Sugimoto Y, Ueno M (1987) Distribution of dung pats and ungrazed areas in Bahiagrass (Paspalum notatum Flügge) pasture. J Jpn Soc Grassland Sci 33:128-139

Hirata M, Sugimoto Y, Ueno M (1991) Use of a mathematical model to evaluate the effects of dung from grazing animals on pasture production and utilization and animal production. J Jpn Soc Grassland Sci 37: 303-323

Huber-Sannwald E, Jackson RB (2001) Heterogeneous soilresource distribution and plant responses-from individual-plant growth to ecosystem functioning. Progress Bot 62:451-476

Jaramillo VJ, Detling JK (1992) Small-scale heterogeneity in a semi-arid North American grassland. I. Tillering, $\mathrm{N}$-uptake and retranslocation in simulated urine patches. J Appl Ecol 29:1-8

Kirkham FW, Kent M (1997) Soil seed bank composition in relation to the above-ground vegetation in fertilized and unfertilized hay meadows on a Somerset peat moor. J Appl Ecol 34:889-902

Krysl LJ, Hess BW (1993) Influence of supplementation on behavior of grazing cattle. J Anim Sci 71:2546-2555

Landsberg J, James CD, Maconochie J, Nicholls AO, Stol J, Tynan R (2002) Scale-related effects of grazing on native plant communities in an arid rangeland region of South Australia. J Appl Ecol 39:427-444

Lantinga EA, Keuning JA, Groenwold J, Deenen PJAG (1987) Distribution of excreted nitrogen by grazing cattle and its effects on sward quality, herbage production and utilization. In: van der Meer HG (ed) Animal manure on grassland and fodder crops. Martinus Nijhoff Publishers, Dordrecht, pp 103-117

Lark RM (2002) Robust estimation of the pseudo cross-variogram for cokriging soil properties. Eur J Soil Sci 53: 253-270

Linnane MI, Brereton AJ, Giller PS (2001) Seasonal changes in circadian grazing patterns of Kerry cows (Bos taurus) in semi-feral conditions in Killarney National Park, Co. Kerry, Ireland. Appl Anim Behav Sci 71:177-292 
Luetge BU, Hatch GP, Hardy MB (1995) The influence of urine and dung deposition on patch grazing patterns of cattle and sheep in the Southern Tall Grassveld. African J Range Forage Sci 12:104-110

MacDiarmid BN, Watkin BR (1971) The cattle dung patch. J Br Grassland Soc 26:239-245

Marten GC, Donker JD (1964) Selective grazing induced by animal excreta I. Evidence of occurrence and superficial remedy. J Dairy Sci 47:773-777

Papritz A, Künsch HR, Webster R (1993) On the pseudo crossvariogram. Math Geol 25:1015-1026

Pebesma EJ (2004) Multivariable geostatistics in S: the gstat package. Comput Geosci 30:683-691

Petersen RG, Lucas HL, Woodhouse WW (1956) The distribution of excreta by freely grazing cattle and its effect on pasture fertility. I. Excretal distribution. Agron J 48: 440-444

Peterson PR, Gerrish JR (1995) Grazing management affects manure distribution by beef cattle. In: Proc. Am. Forage Grassland Council, Lexington, pp 170-174

Radeloff VC, Miller FT, He HS, Mladenoff DJ (2000) Periodicity in spatial data and geostatistical models: autocorrelation between patches. Ecography 23:81-91

Richards IR, Wolton KM (1976) The spatial distribution of excreta under intensive cattle grazing. J Br Grassland Soc 31:89-92

Schnyder H, Locher F, Auerswald K (this volume) Nutrient cycling by grazing cattle controls soil $\mathrm{N}$ and $\mathrm{P}$ patterns and vegetation nutrient status in a low-input pasture ecosystem. Nutr Cycl Agroecosys

Shiyomi M, Okada M, Takahashi S, Tang YH (1998) Spatial pattern changes in aboveground plant biomass in a grazing pasture. Ecol Res 13:313-322

Silverman BW (1986) Density estimation for statistics and data analysis, Monographs on Statistics and Applied Probability. Chapman and Hall, London
Sinowski W, Auerswald K (1999) Using relief parameters in a discriminant analysis to stratify geological areas of different spatial variability of soil properties. Geoderma 89:113-128

Steffee WP, Anderson CF, Young VR (1981) An evaluation of the diurnal rhythm of urea excretion in healthy young adults. J Parenter Enteral Nutr 5:378-384

Thiessen AH, Alter JC (1911) Climatological Data for July, 1911: District No. 10, Great Basin. Mon Weather Rev 1911:1082-1089

Van Groenigen JW, Stein A (1998) Constrained optimization of spatial sampling using continuous simulated annealing. J Environ Qual 27:1078-1086

Van Soest PJ (1994) Nutritional ecology of the ruminant. Cornell University Press, Ithaca

Victor N (1978) Alternativen zum klassischen Histogramm. Methods Inform Med 17:120-126

Voltz M, Webster R (1990) A comparison of kriging, cubic splines and classification for predicting soil properties from sample information. J Soil Sci 41:473-490

Warren SD, Mitasova H, Auerswald K, Hohmann MG (2004) An evaluation of methods to determine slope using digital elevation data. Catena 58:215-233

White SL, Sheffield RE, Washburn SP, King LD, Green JT (2001) Spatial and time distribution of dairy cattle excreta in an intensive pasture system. J Environ Qual 30:21802187

Whitehead DC (2000) Nutrient elements in grassland. CABI Publishing, Wallingford

Zimmerman DL (1993) Another look at anisotropy in geostatistics. Math Geol 25:453-470 